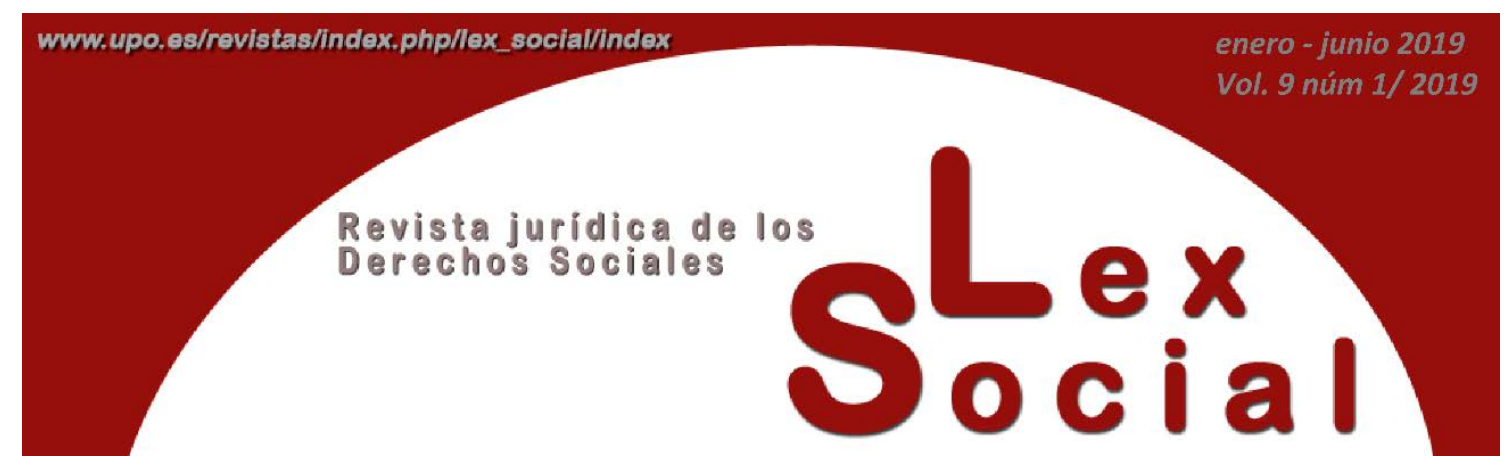

\title{
EL SINUOSO E INCONCLUSO PROCESO DE ADHESIÓN DE ESPAÑA A LA CARTA SOCIAL EUROPEA: RESISTENCIAS, IMPERFECCIONES Y RETOS DE FUTURO
}

\section{SPAIN'S SINUOUS AND UNFINISHED PROCESS OF ADHESION TO THE EUROPEAN SOCIAL CHARTER: RESISTANCES, IMPERFECTIONS AND FUTURE CHALLENGES}

DR. GUILLERMO GARCÍA GONZÁLEZ

Profesor Agregado de Derecho del Trabajo y de la Seguridad Social

Universidad Internacional de La Rioja (UNIR)

Artículo recibido el 1 de marzo de 2019

Artículo aceptado el 8 de marzo de 2019

\section{RESUMEN}

La relación de España con la Carta Social Europea (CSE) ha venido marcada por la indiferencia y por la ausencia de compromiso. Cuando en 1978 España se adhiere al Tratado, las esperanzas eran muchas. Sin embargo, durante estas cuatro décadas, la CSE ha ido penetrando en nuestro ordenamiento jurídico de forma esporádica, inconexa y con escasa coherencia. Las razones que pueden explicar esta situación son muchas, pero, sobre todas ellas, la escasa relevancia que ha venido teniendo la CSE en España debe ser ligada necesariamente al reducido interés que ha suscitado este Tratado en la clase política.

Esta situación se ha revertido, siquiera parcialmente, en los últimos años; y ello, por las resoluciones de ciertos jueces y tribunales que, en un entorno de crisis 
económica y de progresiva laminación de los derechos sociales, toman conciencia de la CSE y proceden a aplicarla como estándar de protección más favorable, declarando inaplicable la legislación nacional en algunos de los casos enjuiciados por ser contraria al compromiso internacional asumido por España. Esta labor judicial desencadena un repentino interés de los actores políticos por la CSE, que se ha visto finalmente materializado, aunque de modo imperfecto y fragmentado, en el Acuerdo del Consejo de Ministros de 1 de febrero de 2019.

Palabras Clave: Carta Social Europea, Consejo de Europa, derechos sociales, tratados internacionales.

\begin{abstract}
Spain's relationship with the European Social Charter has been characterised by inddiference and a lack of commitment. When Spain joined the Treaty in 1978, hopes were high. However, during these four decades, the European Social Charter has been occasionally penetrating our legal system, in a totally unconnected way and with little coherence. There are many reasons for this situation, but, above all, the poor relevance of the European Social Charter in Spain must necessarily be linked to the low level of interest that this Treaty has aroused in the political class. This situation has been reverted, at least partially, in recent years, by the decisions of certain judges and courts who, in a context of economic crisis and progressive curtailment of social rights, are becoming aware of the European Social Charter and proceed to apply it as a more favourable standard of protection. They also declare national legislation to be inapplicable to some of the cases that have been arraigned because it contravenes Spain's international commitment. This judicial work has triggered a sudden interest on the part of political actors in the European Social Charter, which has finally culminated, albeit in an imperfect and fragmented way, in the Agreement of the Council of Ministers dated on 1 February 2019.
\end{abstract}

KEY WoRDS: European Social Charter, Council of Europe, social rights, international treaties. 
SUMARIO

1. ALCANCE Y SIGNIFICADO DE LA CARTA SOCIAL EUROPEA EN LA EUROPA DE LOS DERECHOS SOCIALES

\section{LA CARTA SOCIAL EUROPEA ORIGINARIA Y SUS PROTOCOLOS}

3. LA CARTA SOCIAL EUROPEA REVISADA

\section{LAS GARANTÍAS DE EFICACIA DE LA CARTA SOCIAL EUROPEA}

4.1. El sistema de informes

4.2. El procedimiento de reclamaciones colectivas

5. EL INGRESO DE ESPAÑA EN EL CONSEJO DE EUROPA: FIRMA Y RATIFICACIÓN DE LA CARTA SOCIAL EUROPEA ORIGINARIA

6. FIRMA Y RATIFICACIÓN POR ESPAÑA DE LOS PROTOCOLOS DE 1988 Y 1991

7. ESPAÑA Y SUS RETOS PENDIENTES: EL PROTOCOLO DE RECLAMACIONES COLECTIVAS Y LA CARTA SOCIAL EUROPEA REVISADA

8. EL (PEN)ÚLTIMO INTENTO: EL TÍMIDO E INCOMPLETO COMPROMISO DEL ACUERDO DEL CONSEJO DE MINISTROS DE 1 DE FEBRERO DE 2019

9. A MODO DE CONCLUSIÓN

BIBLIOGRAFÍA

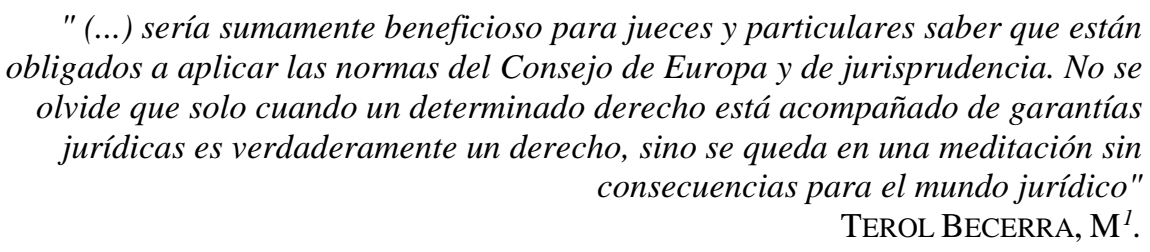

\section{ALCANCE Y SIGNIFICADO DE LA CARTA SOCIAL EUROPEA EN LA EUROPA DE LOS DERECHOS SOCIALES}

Los derechos humanos, debido a su propia naturaleza, han sido tradicionalmente una de las materias a las que el derecho internacional ha prestado singular atención. En el ámbito

\footnotetext{
1 "Sobre la reforma de la Constitución Española de 1978", Lex Social, Revista de los derechos sociales, ${ }^{\circ}$ 1 (2015), p. 116.
} 
europeo, los derechos humanos constituyen el núcleo esencial de la cultura jurídica contemporánea, configurándose como pilar fundamental sobre el que se han cimentado en Europa sistemas, organismos e instituciones supranacionales dirigidos al reconocimiento, protección y salvaguarda de tales derechos. Esta estructura institucional supranacional, conformada en buena parte a partir de la acción del Consejo de Europa, se ha constituido para los ciudadanos europeos en un cauce de referencia para la defensa y garantía de sus derechos humanos y libertades fundamentales.

Enmarcada en la acción del Consejo de Europa, la Carta Social Europea (CSE) es un tratado internacional que fue firmado en su versión originaria en Turín el 18 de octubre de 1961, entrando en vigor el 26 de febrero de 1965, como complemento del Convenio Europeo para la Protección de los Derechos Humanos y de las Libertades Fundamentales (CEDH), acordado en Roma el 4 de noviembre de 1950. La CSE contiene la declaración de derechos sociales más completa del ámbito europeo, y su alcance supera en este sentido a otros instrumentos, como la Carta Comunitaria de los Derechos Fundamentales de los Trabajadores y la Carta de los Derechos Fundamentales de la Unión Europea².

La CSE se presenta como el instrumento "más emblemático del derecho europeo de los derechos sociales o, si se prefiere, del derecho social de los derechos humanos" ${ }^{3}$, constituyendo un complemento indispensable del CEDH, al integrar las lagunas de este en cuanto a los derechos sociales. Se perfecciona, en consecuencia, con la CSE, un sistema europeo de protección de los derechos humanos en toda su extensión, cumpliendo con ello, al menos en un plano de técnica jurídica, el principio de indivisibilidad de los derechos humanos en el ámbito europeo ${ }^{4}$.

Ambos instrumentos, CEDH y CSE, se incardinan en la denominada fase de humanización del derecho internacional contemporáneo ${ }^{5}$, si bien presentan notables asimetrías entre ellos, que, de facto, dificultan la perseguida indivisibilidad de los derechos humanos ${ }^{6}$. Con todo, y sin desconocer las diferencias sustanciales que separan ambos tratados, y que principalmente residen en sus procedimientos de control y cumplimiento, tanto el CEDH como la CSE obedecen a la misma finalidad esencial, no

\footnotetext{
2 JIMENA QUESADA, L., "La Carta Social Europea como instrumento de democracia social en Europa y en España", en JIMENA QUESADA, L. (coord.), Escritos sobre derecho europeo de los derechos sociales, Valencia, Tirant lo Blanch, 2004, p. 137.

3 JIMENA QUESADA, L. y SALCEDO BELTRÁN, C., "Desafíos para la protección de los derechos sociales en Europa: la Carta Social Europea", Revista de Administración Pública, vol. 47 (2016), p. 276.

${ }^{4}$ Sobre este punto, cfr. MONEREO PÉREZ, J.L., "El principio de indivisibilidad e interdependencia en el sistema jurídico internacional multinivel de garantía de los derechos fundamentales", Revista Derecho del Trabajo, $\mathrm{n}^{\circ} 15$ (2017), pp. 21-68.

${ }^{5}$ DíEZ DE VELASCO VALLEJO, M., Instituciones de Derecho Internacional Público, Madrid, Tecnos, $15^{\mathrm{a}}$ ed., 2005, pp. 64-66.

${ }^{6}$ JIMENA QUESADA, L. y SALCEDO BELTRÁN, C., "Desafíos para la...", op. cit., p. 277.
} 
resultando posible una interpretación aislada de sus contenidos ${ }^{7}$. La necesaria interpretación conjunta de ambos instrumentos deriva directamente, como ha sido apuntado, de la indivisibilidad de los derechos humanos, que imposibilita considerar a los derechos civiles y políticos y a los derechos económicos y sociales como compartimentos estancos. En última instancia, la clasificación de los derechos humanos y su categorización como civiles y políticos o socioeconómicos no deja de ser una distinción un tanto artificiosa, estando ambas categorías íntimamente ligadas y concurriendo, además, derechos cuya fisiología imposibilita su incardinación en una u otra categoría, ostentando en este sentido una verdadera naturaleza mixta ${ }^{8}$.

El sistema de reconocimiento y protección de los derechos sociales implementado por la CSE se vincula necesariamente con los mecanismos de consagración y salvaguarda de los derechos humanos en general, reforzando la necesaria interrelación e indivisibilidad de todos los derechos humanos, con independencia de su clasificación o tipología. La propia CSE revisada, señala la necesidad de "preservar la naturaleza indivisible de todos los derechos humanos, sean derechos civiles, políticos, económicos, sociales o culturales" ${ }^{9}$.

Aunque de su denominación pueda parecer que la CSE está conformada por un único documento, realmente se configura por cinco documentos distintos: la CSE en su versión originaria, tres protocolos y la CSE revisada. Tanto los protocolos, singularmente el referido al procedimiento de reclamaciones colectivas, como la CSE revisada, no han sido ratificados por todos los Estados miembros del Consejo de Europa, lo que implica que la CSE originaria siga teniendo plena eficacia.

En la actualidad, cuarenta y tres países europeos de los cuarenta y siete que conforman el Consejo de Europa han ratificado la CSE originaria y/o revisada. Entre ellos, todos los países de la Unión Europea sin excepción han procedido a ratificarla en su versión original y/o revisada. De los países pertenecientes al Consejo de Europa, solo Liechtenstein, Mónaco, San Marino y Suiza no han ratificado la CSE; ratificación esta que no resulta obligatoria para poder ser miembro de pleno derecho de dicha institución supranacional, a diferencia de lo que ocurre en el caso del CEDH, extremo que ha merecido duras críticas por parte de la doctrina más autorizada ${ }^{10}$.

\footnotetext{
${ }^{7}$ RODRÍGUEZ PIÑERO, M., "La Carta Social Europea y la problemática de su aplicación", Revista de Política Social, no 118 (1978), pp. 6 y 7. Vid. el excelente análisis de CARRILLO SALCEDO, J.A., "Protección de los derechos humanos en el Consejo de Europa: hacia la superación de la dualidad entre derechos civiles y políticos y derechos económicos y sociales", Revista de Instituciones Europeas, vol. 18, $n^{\circ} 2$ (1991), pp. 431-454.

8 SANZ CABALLERO, S., "Sobre las prolongaciones sociales del Convenio Europeo de Derechos humanos: la invocación del acervo de la Organización Internacional del Trabajo en la jurisprudencia del Tribunal Europeo de Derechos Humanos", Revista General de Derecho Europeo, no 32 (2014), p. 3.

${ }^{9}$ Preámbulo de la CSE revisada.

10 JIMENA QUESADA, L., "La Carta Social Europea y la Unión Europea", Revista Europea de Derechos Fundamentales, no 13 (2009), pp. 404-405.
} 
La indudable relevancia de la CSE como "instrumento internacional que contiene el más completo catálogo de derechos sociales" ${ }^{11}$, no se ha visto reflejada en la práctica por diferentes motivos. Los déficits internos del propio Tratado, reflejados en sus mejorables mecanismos de control de cumplimiento, han generado una recepción de sus contenidos en la práctica jurídica interna más lenta e imperfecta en comparación con otros instrumentos internacionales. A ello se debe añadir "la omnipresencia del derecho de la Unión Europea", que origina frecuentemente que la CSE "sea ignorada, confundida e incluso encuadrada en el mismo"12, lo que ha dado lugar a la existencia de "dos verdades sociales europeas" ${ }^{13}$.

Sin perjuicio de lo anterior, la principal causa del escaso impacto que la CSE ha tenido en España se debe encontrar en el exiguo interés que en el ámbito político e institucional ha despertado este Tratado desde que fue firmado por nuestro país en 1978. Esta situación se ha revertido, siquiera parcialmente, en los últimos años; y ello, debido a las resoluciones de algunos jueces y tribunales que, en un entorno de crisis económica y de progresiva laminación de los derechos sociales, toman conciencia de la CSE y proceden a aplicarla como estándar de protección más favorable, declarando inaplicable la legislación nacional en algunos de los casos enjuiciados, por ser contraria al compromiso internacional asumido por España. Esta labor judicial, de relevancia mediática en un contexto de cuestionamiento social de las reformas laborales operadas, desencadena un repentino interés de los actores políticos por la CSE.

\section{LA CARTA SOCIAL EUROPEA ORIGINARIA Y SUS PROTOCOLOS}

La CSE fue firmada en su versión originaria en Turín el 18 de octubre de 1961 y entró en vigor el 26 de febrero de $1965^{14}$. Se estructura en un preámbulo, cinco partes y un anexo.

La parte I, de carácter meramente declarativo, enuncia diecinueve principios que deben orientar la acción social de los Estados firmantes y que se plasman jurídicamente en la parte II, integrada por diecinueve artículos, que contiene los derechos y deberes de las Partes. Así, se enumeran las obligaciones de los Estados de garantizar el efectivo derecho al trabajo (art. 1), unas condiciones de trabajo justas (art. 2), la seguridad e higiene en el trabajo (art. 3), una remuneración justa (art. 4), el derecho a la libertad sindical (art. 5), la negociación colectiva (art. 6), la protección de niños y adolescentes (art. 7), la protección de las trabajadoras (art. 8), la orientación y formación profesional (arts. 9 y 10), la

\footnotetext{
${ }^{11}$ BELORGEY, J.M., "La Carta Social Europea del Consejo de Europa y su órgano de control: el Comité Europeo de Derechos Sociales", Revista de Derecho Político, no 70 (2007), p. 349.

${ }^{12}$ SALCEDO BELTRAN, C., Reformas legislativas, incumplimientos de la Carta Social Europea y su invocación en los órganos judiciales, Sevilla, Centro de Estudios Andaluces, 2015, p. 8.

${ }^{13}$ JIMENA QUESADA, L., "La Carta Social Europea...", op. cit., p. 398.

${ }^{14}$ Sobre el proceso de elaboración del tratado, vid. el completo estudio de RODRÍGUEZ PIÑERO, M., "Antecedentes, génesis y significado de la Carta Social Europea", Revista de Política Social, nº 53 (1962), pp. 133-195.
} 
protección de la salud (art. 11), la seguridad social (art. 12), la asistencia social y médica (art. 13), los beneficios de los servicios sociales (art. 14), la formación profesional y readaptación profesional y social de las personas física o mentalmente disminuidas (art. 15), el derecho de la familia a una protección social, jurídica y económica (art. 16), el derecho de las madres y los niños a una protección social y económica (art. 17), el derecho a ejercer una actividad lucrativa en el territorio de otras Partes contratantes (art. 18), y, por último, la protección y asistencia de los trabajadores migrantes y sus familias (art. 19).

La parte III hace referencia a las obligaciones de los Estados en relación con la CSE, comprendiendo el singularmente complejo sistema de ratificación de la misma. De acuerdo al art. 20.1 a) y b) de la CSE, los Estados deben ratificar al menos cinco de los siete artículos que se determinan como esenciales, todos ellos recogidos en la parte II de la CSE. Estos siete artículos son los siguientes: el derecho al trabajo (art. 1), el derecho de sindicación (art. 5), el derecho a la negociación colectiva (art. 6), el derecho a la seguridad social (art. 12), el derecho a la asistencia social y médica (art. 13), el derecho de la familia a una protección social, jurídica y económica (art. 16), y el derecho de los trabajadores migrantes y sus familias a la protección y a la asistencia (art. 19). Además, y adicionalmente, los Estados miembros deben ratificar un número complementario de artículos o párrafos numerados de la parte II de la Carta, a su libre elección, siempre que el número total de los artículos y de los párrafos numerados a los que se quede obligado no sea inferior a diez artículos o a cuarenta y cinco párrafos numerados (art. 20.1 c) de la CSE).

Este sistema de ratificación tan dúctil, implica que no todos los Estados firmantes resulten obligados con el mismo alcance y contenido, variando en cada caso sus derechos y obligaciones en atención a los preceptos que cada Estado miembro haya decidido ratificar. Es indudable que la flexibilidad que deriva de este régimen de ratificación genera una mayor adaptabilidad y extensión, siquiera fragmentada, de los principios derivados de la CSE. Además, posibilita la existencia de un consenso de mínimos en la defensa de los derechos sociales en el marco europeo. Sin embargo, no cabe obviar que un mecanismo de ratificación de esta condición, podría derivar en situaciones poco plausibles, facilitando que los Estados opten por ratificar solo aquellos preceptos que no les resulten excesivamente gravosos ${ }^{15}$ y conformando en cada Estado Parte una CSE "a la carta"16.

La parte IV (arts. 21 a 29) comprende la regulación del sistema de control de aplicación de la CSE, articulado a través de la presentación de informes de las Partes contratantes. El ejercicio de este control reside principalmente en el Comité Europeo de Derechos

\footnotetext{
${ }^{15}$ BELORGEY, J.M., "La Carta Social Europea del Consejo...", op. cit., p. 351.

${ }^{16}$ CASTILLO DAUDÍ, M., "La Carta Social Europea treinta años después: el Protocolo de 21 de octubre de 1991", Tribuna Social, no 27 (1993), p. 22.
} 
Sociales (CEDS), que está formado por quince expertos independientes e imparciales, elegidos por el Comité de Ministros para un mandato de duración de seis años, con una posible renovación.

La parte V (arts. 30 a 38) se ocupa de la suspensión de las obligaciones asumidas por los Estados en caso de guerra o peligro público, de las restricciones de su aplicación necesarias en una sociedad democrática con el fin de garantizar el respeto de los derechos y libertades de terceros o para proteger el orden público, la seguridad nacional, la salud pública o las buenas costumbres (art. 31), las relaciones de la CSE y el derecho interno y los acuerdos internacionales (art. 32), la aplicación de la CSE por los convenios colectivos (art. 33), el ámbito territorial de la misma (art. 34), su firma, ratificación y entrada en vigor (art. 35), la presentación de enmiendas (art. 36), y su denuncia (art. 37). Por último, el anexo (formalmente el art. 38 y último de la CSE) incluye criterios hermenéuticos para la correcta interpretación de algunos preceptos de la CSE.

La CSE se ha visto completada con tres protocolos. El primero de ellos, Protocolo adicional, fue firmado en Estrasburgo el 5 de mayo de 1988, con la finalidad de extender la protección de los derechos sociales y económicos garantizados por la CSE. Mediante este Protocolo se añaden cuatro nuevos derechos a los contenidos en la CSE: derecho a la igualdad de oportunidades y a la igualdad de trato en materias de empleo y ocupación sin discriminación por razón de sexo (art. 1), derecho a la información y consulta dentro de la empresa (art. 2), derechos a participar en la determinación y mejora de las condiciones de trabajo y del entorno de trabajo (art. 3), y derecho de las personas mayores a la protección social (art. 4).

El segundo protocolo o Protocolo de enmienda, suscrito en Turín el 21 de octubre de 1991, está dirigido a mejorar los mecanismos de control del cumplimiento por los Estados de la CSE, incrementando su efectividad. Su propósito consiste en mejorar la eficacia de la Carta, y, en particular, su mecanismo de control. El Protocolo de enmienda no ha entrado en vigor formalmente, pues necesita para ello el consentimiento unánime de todos los Estados Partes de la CSE, extremo que no se ha producido hasta la fecha. Con independencia de su eficacia formal, en la práctica, casi la totalidad de sus disposiciones están siendo aplicadas por los órganos de control, conforme a la decisión del Comité de Ministros de 1991 (467 a reunión de los Delegados de los Ministros de diciembre de 1991). En esta decisión, se solicitaba a los órganos de control de la CSE que aplicaran los contenidos del Protocolo, incluso antes de que este entrara formalmente en vigor, en la medida en que fueran compatibles con el texto de la norma. De este modo, todas las disposiciones del Protocolo de 1991 resultan aplicables, excepto la elección de miembros 
del CEDS por la Asamblea Parlamentaria, elección que sigue siendo realizada por el Comité de Ministros ${ }^{17}$.

El último Protocolo fue firmado el 9 de noviembre de 1995 en Estrasburgo, y se ocupa de conformar un sistema de quejas colectivas. Tiene como objetivo reforzar la efectividad de los derechos consagrados en la CSE, fomentando la participación de los empresarios y trabajadores, así como de las organizaciones no gubernamentales con estatuto participativo en el Consejo de Europa. Este Protocolo, calificado como revolucionario desde el punto de vista procedimental, crea un procedimiento de control abierto a entidades no estatales, que se añade al mecanismo tradicional de control original contenido en la Carta de $1961^{18}$.

\section{LA CARTA SOCIAL EUROPEA REVISADA}

La CSE revisada, firmada el 3 de mayo de 1996 en Estrasburgo, refleja todos los cambios introducidos por los tres Protocolos, junto con las interpretaciones que del texto convencional se habían ido generando por la labor de las resoluciones del CEDS. Su arquitectura es similar a la de la CSE originaria, teniendo la parte I treinta y un puntos de carácter programático, que se corresponden con los treinta y un artículos vinculantes de la parte II.

Además, la CSE añade ocho nuevos derechos sociales a la parte II (arts. 24 a 31): derecho a protección en caso de despido, derecho de los trabajadores a la protección de sus créditos en caso de insolvencia de su empresario, derecho a la dignidad en el trabajo, derecho de los trabajadores con responsabilidades familiares a la igualdad de oportunidades y a la igualdad de trabajo, derecho de los representantes de los trabajadores a protección en la empresa y facilidades que se les deberían conceder, derecho a información y consulta en los procedimientos de despido colectivo, derecho a protección contra la pobreza y la exclusión social, y derecho a la vivienda.

Como la CSE revisada amplía los derechos y obligaciones de los Estados Partes en relación con la CSE originaria, se exige que los Estados ratifiquen también esta nueva versión. Para ello, la parte III, artículo A, de la CSE revisada, exige a los Estados que consideren "la Parte I de la presente Carta como una declaración de los objetivos que tratará de alcanzar por todos los medios adecuados", y a que se obliguen "por al menos seis de los nueve artículos siguientes de la Parte II de la Carta: artículos 1, 5, 6, 7, 12, 13,

\footnotetext{
${ }^{17}$ Vid. JIMENA QUESADA, L., "Retos pendientes del estado social español: en especial, la ratificación de la Carta Social Europea revisada de 1996", Nuevas Políticas Públicas: Anuario multidisciplinar para la modernización de las Administraciones Públicas, $\mathrm{n}^{\circ} 2$ (2006), pp. 51-52.

${ }^{18}$ Cfr. TEIXEIRA ALVES, L., El cumplimiento de la Carta Social Europea en materia de salarios: un estudio comparado de los ordenamientos laborales portugués, español e italiano, Barcelona, Atelier, 2014, pp. 15 y ss.
} 
16, 19 y 20". Estos artículos se corresponden con el denominado núcleo duro de la Carta, y se concretan en los siguientes derechos: derecho al trabajo (art. 1), derecho sindical (art. 5), derecho de negociación colectiva (art. 6), derecho de los niños y adolescentes a protección (art. 7), derecho a la seguridad social (art. 12), derecho a la asistencia social y médica (art. 13), derecho de la familia a protección social, jurídica y económica (art. 16), derecho de los trabajadores migrantes y sus familias a protección y asistencia (art. 19), y derecho a la igualdad de oportunidades y de trato en materia de empleo y de profesión, sin discriminación por razón del sexo (art. 20). Además, y siguiendo la lógica de la CSE originaria, los Estados Partes deberán obligarse por un número adicional de artículos o párrafos numerados de la parte II de la Carta a su elección, "siempre que el número total de los artículos y de los párrafos numerados a los que quedará obligada no sea inferior a dieciséis artículos o a sesenta y tres párrafos numerados" (artículo A, parte III, de la CSE revisada).

La CSE revisada ha merecido valoraciones muy positivas por la ampliación de derechos que conlleva, si bien sigue adoleciendo de los déficits que tradicionalmente venía arrastrando en cuanto a los sistemas de control implementados para su cumplimiento ${ }^{19}$. Especialmente relevante es la posibilidad que abre la CSE revisada de ratificar su contenido sin necesidad de obligarse previamente al Protocolo de reclamaciones colectivas de 1995. En relación con este punto, la doctrina más autorizada ha señalado que "hubiera sido deseable que se estableciera de forma generalizada su carácter obligatorio a cualquier parte contratante que ratificara la CSE revisada, sin necesidad de realizar una adhesión ad hoc del Protocolo de reclamaciones colectivas o de la declaración específica" $^{20}$.

\section{LAS GARANTÍAS DE EFICACIA DE LA CARTA SOCIAL EUROPEA}

El grado de eficacia de cualquier norma jurídica internacional deriva en gran medida de los mecanismos de control de cumplimiento que por la misma se implementen. La CSE conforma dos mecanismos de control de su cumplimiento: el sistema de informes y el procedimiento de reclamaciones colectivas ${ }^{21}$.

\subsection{El sistema de informes}

El sistema de informes resulta aplicable a todos los Estados que han ratificado la CSE, originaria y/o revisada. Su regulación se encuentra en la parte IV (arts. 25 a 29) de la

\footnotetext{
${ }^{19}$ Vid. VALDÉS DAL-RÉ, F., El constitucionalismo laboral europeo y la protección multinivuel de los derechos laborales fundamentales: luces y sombras, Albacete, Bomarzo, 2016, pp. 53-59.

20 SALCEDO BELTRAN, C., Reformas legislativas, incumplimientos de la Carta Social Europea y su invocación en los órganos judiciales, op. cit, p. 11.

${ }^{21}$ Procedimientos que, al menos inicialmente, estuvieron muy influenciados por "el espíritu de la OIT". CASTILLO DAUDÍ, M., "La Carta Social Europea...", op. cit, p. 22.
} 
CSE. Las Partes contratantes le remiten al CEDS anualmente un informe explicativo del modo en que se está observando la CSE en su país, tanto en la legislación interna como en la práctica. Como se ha apuntado anteriormente, el CEDS es el máximo órgano de interpretación, defensa y control del cumplimiento de la CSE por los Estados Partes, estando compuesto por quince expertos independientes elegidos por el Comité de Ministros y resultando asimilable al Tribunal Europeo de Derechos Humanos con respecto al $\mathrm{CEDH}^{22}$.

El informe no se extiende a todos los contenidos de la CSE, sino que se centra en el grupo temático que anualmente proceda: grupo 1, sobre empleo, formación e igualdad de oportunidades, grupo 2, sobre salud, seguridad social y protección social, grupo 3, sobre derechos relacionados con el trabajo, y grupo 4, sobre niños, familia y migrantes. De este modo, cada grupo de materias será analizado una vez cada cuatro años. Los Estados están obligados a enviar a las organizaciones sindicales y empresariales más representativas de ámbito nacional copia de estos informes, pudiendo estas presentar observaciones a los mismos. Ello implica la posibilidad de que los agentes sociales aporten información adicional a la incluida en los informes gubernamentales, y constituye un mecanismo que facilita su participación en el sistema de la CSE, de especial relevancia en aquellos Estados que no hayan ratificado el Protocolo de 1995 de reclamaciones colectivas, como es el caso de España ${ }^{23}$. Examinada la documentación, y durante el año siguiente a su presentación, el CEDS emite una conclusión que determina la conformidad o no del país con la CSE (originaria o revisada) y con el Protocolo de 1988. Si no se apreciara conformidad, la conclusión del CEDS impondrá medidas de mejora o corrección.

Hechas públicas las conclusiones, el Comité Gubernamental, compuesto por un representante de los Gobiernos de cada una de las Partes contratantes, supervisa el cumplimiento de las mismas y emite un informe dirigido al Comité de Ministros. El Comité de Ministros, formado por los ministros de asuntos exteriores de todos los Estados miembros o sus representantes permanentes, y en su condición de órgano decisorio del Consejo de Europa, puede emitir una recomendación solicitando el Estado en cuestión que modifique y adapte su normativa a la CSE, si así lo decidieran dos tercios de sus miembros.

El sistema de informes ha generado múltiples objeciones por parte de la doctrina. Así, y entre otros déficits, se ha señalado que el sistema de informes impone un control político

\footnotetext{
22 JIMENA QUESADA, L., "El Comité Europeo de Derechos Sociales: sinergias e impacto en el sistema internacional de Derechos Humanos y en los ordenamientos nacionales", Revista Europea de Derechos Fundamentales, $\mathrm{n}^{\circ} 25$ (2015), p. 104.

${ }^{23}$ CARDONA RUBERT, M. B., "La situación del Estado español en relación al cumplimiento de la Carta Social Europea", Revista de Derecho Social, n ${ }^{\circ} 69$ (2015), p. 106. No obstante, en pocas ocasiones se presentan observaciones por los agentes sociales a los informes gubernamentales. Cfr. PRIETO SUÁREZ, R., "La Carta Social Europea y el Comité Europeo de Derechos Sociales (el sistema de informes y las reclamaciones colectivas)", Revista Europea de Derechos Fundamentales, no 11 (2008), p. 360.
} 
sobre la ejecución de las decisiones del CEDS, ejecución que en último término dependerá de la voluntad política de los Estados ${ }^{24}$. También se ha incidido en que la revisión cuatrienal de la CSE impide reaccionar de modo ágil y eficaz frente a situaciones nacionales que requieran una respuesta rápida, y en la escasa eficacia que, de facto, tienen las recomendaciones del Comité de Ministros en relación con los Estados Partes a los que van dirigidas ${ }^{25}$. Con el fin de subsanar algunas de estas deficiencias, en el año 2014 se introduce una reforma del sistema de informes, implementando un sistema simplificado de aplicación exclusiva a los Estados que hayan ratificado el procedimiento de reclamaciones colectivas.

\subsection{El procedimiento de reclamaciones colectivas}

El procedimiento de reclamaciones colectivas es el segundo mecanismo de control de la CSE, teniendo, frente al procedimiento de informes, carácter facultativo para los Estados Partes. Este procedimiento solo puede ser utilizado por los países que hayan ratificado el Protocolo de 1995 que lo regula, o por los Estados que realicen una adhesión expresa al suscribir la CSE, originaria y/revisada (parte IV, art. D.2). Ninguna de estas circunstancias concurren en el caso de España.

Como de su propia denominación se deduce, las reclamaciones articuladas mediante este procedimiento deben tener carácter colectivo, no siendo admisible ningún tipo de reclamación de carácter individual. El carácter colectivo de la reclamación dota al procedimiento de un indudable efecto preventivo de futuros litigios internos de carácter individual $^{26}$.

Este procedimiento de control de la CSE puede ser considerado como el más importante y eficaz, teniendo en cuenta la celeridad y simplicidad en su tramitación y su consecuente potencial de justiciabilidad y efectividad ${ }^{27}$. El procedimiento se estructura de modo análogo a un procedimiento judicial o cuasi judicial de carácter contradictorio ${ }^{28}$. La legitimación para interponer una reclamación se atribuye a: organizaciones internacionales de empleadores y de trabajadores, organizaciones nacionales representativas sometidas a la jurisdicción de la Parte contratante contra la que se dirige la reclamación, organizaciones internacionales no gubernamentales reconocidas como

\footnotetext{
${ }^{24}$ Ibíd., p. 361.

${ }^{25}$ JIMENA QUESADA, L., "El Comité Europeo de Derechos Sociales: sinergias...", op. cit., p. 105.

${ }^{26}$ BELORGEY, J.M., "La Carta Social Europea del Consejo...", op. cit., p. 356.

${ }^{27}$ Extremo que se evidencia en los plazos medios de admisibilidad de las reclamaciones (cuatro meses) y de resolución sobre el fondo del asunto (siete meses). JIMENA QUESADA, L., "El Comité Europeo de Derechos Sociales: sinergias...", op. cit., p. 105.

${ }^{28}$ PRIETO SUÁREZ, R., "La Carta Social Europea...", op. cit., p. 362 y JIMENA QUESADA, L., "La armonización procesal europea en materia de derechos fundamentales tras el Tratado de Lisboa: el caso de los derechos sociales", en DE LA OLIVA SANTOS, A. y CALDERÓN CUADRADO, M.P., La Armonización del Derecho Procesal tras el Tratado de Lisboa, Cizur Menor, Aranzadi, 2012, p. 46.
} 
entidades consultivas por el Consejo de Europa y que figuren en la lista elaborada por el Comité Gubernamental, así como a cualquier organización nacional no gubernamental no representativa a la que reconozca un Estado Parte el derecho a presentar reclamaciones. La reclamación se presenta por escrito, y para su interposición no es necesario el agotamiento previo de los procedimientos jurisdiccionales nacionales. El escrito debe contener los preceptos de la CSE que no están siendo observados por el Estado, sujeto pasivo de la reclamación; y ello, no solo en atención a los incumplimientos de la CSE que deriven de los textos legales o reglamentarios internos, sino también de las prácticas seguidas en relación con los derechos garantizados por el Tratado ${ }^{29}$.

El procedimiento se tramita ante el CEDS, que actúa bajo parámetros jurisdiccionales ${ }^{30}$. Examinada su admisibilidad, y si resulta admitida la reclamación, se prevé la posibilidad de adoptar excepcionalmente medidas inmediatas en evitación de daños irreparables y garantía de los derechos sociales reconocidos en la CSE.

El procedimiento se desarrolla normalmente por escrito, aunque es posible que el CEDS pueda decidir que tenga lugar una vista pública para que las partes, además de por escrito, expongan oralmente sus argumentos ${ }^{31}$. Analizada la controversia y oídas las partes, el CEDS adopta una decisión sobre el fondo del asunto, a modo de sentencia y con eventuales votos particulares, que es comunicada a las partes intervinientes y al Comité de Ministros ${ }^{32}$. La decisión sobre el fondo del asunto del CEDS tiene la forma de una sentencia. Finaliza el procedimiento con la emisión de una resolución por el Comité de Ministros, y, si procede, de una recomendación en la que concreta la normativa o práctica interna que no es acorde con la CSE, invitando a la adopción de las medidas que procedan. La única obligación del Estado receptor de la comunicación del Comité de Ministros consiste en informar sobre su cumplimiento en el siguiente informe que presente.

\section{EL INGRESO DE ESPAÑA EN EL CONSEJO DE EUROPA: FIRMA Y RATIFICACIÓN DE LA CARTA SOCIAL EUROPEA ORIGINARIA}

El fallecimiento de Francisco Franco, el 20 de noviembre de 1975, pone fin al régimen dictatorial que había venido sufriendo España desde el fin de la Guerra Civil en 1939. Se inicia con la muerte del dictador el periodo conocido en la historia de España como de transición democrática, y que culmina con la aprobación de la Constitución Española (CE) en diciembre de $1978^{33}$. En estos escasos tres años, España gesta múltiples reformas

\footnotetext{
${ }^{29}$ Cfr. BELORGEY, J.M., "La Carta Social Europea del Consejo...", op. cit., p. 354.

${ }^{30}$ PRIETO SUÁREZ, R., "La Carta Social Europea..." op. cit., p. 362.

${ }^{31}$ Ibíd., p. 362.

32 JIMENA QUESADA, L., "La armonización procesal...", op. cit., p. 46

33 Se delimita este periodo atendiendo a la denominada transición institucional, de mucha más fácil concreción temporal que la transición política. Vid. PASTOR ARACIL, M., "Reflexiones sobre la transición política y la consolidación democrática en España", Anuario de la Facultad de Derecho, n 2 (1992-1993), p. 55.
} 
políticas y fija los cimientos para profundas transformaciones que le permitan reintegrarse en un entorno europeo occidental esencialmente democrático. La vocación de reinserción en la sociedad internacional democrática, y singularmente europea, como miembro de pleno derecho, es uno de los pilares en que se fundamenta el proceso de transición vivido en España durante los primeros años del posfranquismo, que vino marcado por su dimensión internacional ${ }^{34}$.

En este contexto histórico, desde los ámbitos de decisión política, aún en proceso de conformación definitiva, se entendía que la integración de España en el Consejo de Europa constituía un instrumento imprescindible para reforzar su proceso de transformación política y su plena integración en la Europa democrática. Resulta evidente que la incorporación al Consejo de Europa no conllevaba la asimilación inmediata y automática de los valores de integración europeos por parte de la sociedad española, pero sí que constituía un gesto político, de indudable valor simbólico, que evidenciaba el giro democrático que se pretendía operar en España ${ }^{35}$.

El significado simbólico apuntado, y que se sintetiza en identificar Europa con modernización y democratización, puede ser considerado como uno de los mitos políticos fundamentales del periodo de transición democrática en España. Así, el mito europeo constituyó un elemento esencial de la política de pactos que sustentó el cambio político en España, dotando, además, a la joven democracia española de alta legitimidad ${ }^{36}$. Se asumía, por tanto, la máxima de José Ortega y Gasset que consideraba a España el problema y a Europa la solución, y que había permeado en el pensamiento colectivo de la sociedad civil ${ }^{37}$.

Durante el régimen franquista, el Consejo de Europa había tenido una actitud muy crítica hacia el sistema político español, postura que se mantuvo una vez fallecido Francisco Franco, hasta que Adolfo Suárez es nombrado presidente del Gobierno en julio de 1976. Desde ese momento, las tensiones entre el Consejo de Europa y España empiezan a reducirse como consecuencia de la clara vocación democratizadora expresada por el nuevo Gobierno. La victoria de Unión de Centro Democrático (UCD) y de Adolfo Suárez en las primeras elecciones democráticas españolas, el 15 de junio de 1977, llevan a iniciar el proceso de adhesión de España al Consejo de Europa.

El 8 de julio de 1977, la Comisión Permanente del Consejo de Europa se felicitó por la jornada electoral, y encargó al presidente de la Asamblea que invitara al de las Cortes

\footnotetext{
${ }^{34}$ SESMA LANDRIN, N. y DE HOYOS PUENTE, J., "Los procesos de transición democrática a debate", en AA.VV., Ayer y hoy. Debates, historiografía y didáctica de la historia, Valencia, Universidad de Valencia y Asociación de Historia Contemporánea, 2015, p. 149.

${ }^{35}$ Cfr. RAMÍREZ JIMÉNEZ, M. "Reflexiones sobre la transición española a la democracia", Revista de Derecho Político, $\mathrm{n}^{\circ} 31$ (1990), pp. 14-15.

${ }^{36}$ MORÁN, Ma L. "La cultura política y la interpretación de las transiciones a la democracia. Notas sobre el caso español”, Política y Sociedad, no 20 (1995), pp. 97-110.

${ }^{37}$ SEBASTÍAN LORENTE, J.J., "La idea de Europa en el pensamiento político de Ortega y Gasset", Revista de Estudios Políticos, no 83 (1994), p. 223.
} 
Españolas a enviar una delegación de observadores españoles a la próxima reunión de aquel órgano, como paso previo a una vinculación de España con la institución europea ${ }^{38}$. El problema de la admisibilidad de España en el Consejo de Europa residía en aquel momento en determinar si resultaba necesario que nuestro país contara, previamente a su admisión, con un texto constitucional aprobado que garantizara los principios y valores esenciales encarnados por el Consejo de Europa.

El 8 de octubre de 1977, los representantes de todos los grupos parlamentarios del Congreso de los Diputados emiten una declaración formal en la que trasladan al Consejo de Europa su "firme decisión de garantizar constitucionalmente la preeminencia del Derecho, el respeto de los ideales consagrados en el Estatuto del Consejo de Europa y en especial los derechos humanos y las libertades fundamentales recogidos en la Convención Europea firmada en Roma el 4 de noviembre de 1950"39.

La cohesión de los grupos políticos españoles y la contundencia del mensaje emitido hacen que, sin esperar al formalismo de una Constitución, la Asamblea Parlamentaria del Consejo de Europa, el día 12 de octubre de 1977, invite "sin demora a España para que se convierta en el vigésimo Estado miembro del organismo europeo", entrando de este modo "en la familia de Estados democráticos de la Europa occidental"40. Al día siguiente, el Gobierno español emite su solicitud formal de adhesión, siendo aceptada por el Comité de Ministros del Consejo de Europa el 18 de octubre de 1977, mediante su Resolución 77 (32).

Una vez aprobado por unanimidad por el Congreso y el Senado, España se adhiere al Consejo de Europa oficialmente el 24 de noviembre de 1977. Ese mismo día, el ministro de Asuntos Exteriores, Marcelino Oreja, firma en nombre de España el CEDH de 1950. Tras su adhesión, España cumplimenta todas las formalidades necesarias para constituirse en el vigésimo miembro del Consejo de Europa. Así, se conforma la delegación oficial de las Cortes españolas en la Asamblea de Estrasburgo, integrada por diez titulares y diez suplentes, incrementados a doce desde 1978, con José Manuel Otero Madrigal como presidente y Gregorio Peces Barba como vicepresidente, nombrando además, el 25 de abril de 1978, al primer juez español en el Tribunal Europeo de Derechos Humanos, Eduardo García de Enterría. Rápidamente, España va suscribiendo todos los tratados del Consejo de Europa, firmando la CSE el 27 de abril de 1978.

El ágil proceso de adhesión de España al Consejo de Europa y la unanimidad que los países europeos mostraban con relación al mismo, representaba, en último término, un

\footnotetext{
${ }^{38}$ Sobre el proceso de incorporación de España al Consejo de Europa, cfr. el completo estudio de VIÑAL CASAS, A., "Historia de las negociaciones para el ingreso de España en el Consejo de Europa", Revista de Instituciones Europeas, v. 5, no 1 (1978), pp. 93-113.

${ }^{39}$ Esta declaración fue suscrita por Leopoldo Calvo-Sotelo (UCD), Felipe González (PSOE), Manuel Fraga (Alianza Popular), Francisco Ramos Molins (socialistas catalanes), Miquel Roca (Minoría VascoCatalana), Santiago Carrillo (Partido Comunista de España, PCE) y Raúl Morodo (Grupo Mixto).

${ }^{40}$ El País, 13 de octubre de 1977.
} 
respaldo del viejo continente al proceso democratizador iniciado por nuestro país y "el entierro total del régimen franquista" 41 .

La CSE es firmada en Estrasburgo por el plenipotenciario de España el 27 de abril de 1978, siendo ratificada en su versión originaria y en su totalidad el 29 de abril de 1980, y entrando en vigor el 5 de junio de ese mismo año ${ }^{42}$. El proceso de ratificación fue rápido y su trámite y discusión parlamentarios vinieron marcados por la unanimidad y el consenso de los diferentes grupos representados en las Cortes Generales. La doctrina de la época depositó grandes esperanzas en la firma de la CSE por España, principalmente por la capacidad que se atribuía al Tratado para perfeccionar nuestro derecho del trabajo, acercándolo de este modo a los demás sistemas europeos ${ }^{43}$.

Desde el momento de su ratificación, España se vinculó por los derechos y garantías reconocidos en la CSE, ex arts. 96 y 10.2 CE. Además, la ratificación de la CSE trae consigo la sujeción de nuestro país a las interpretaciones que realice el CEDS, que ha de calificarse a estos efectos como jurisprudencia ${ }^{44}$.

\section{FIRMA Y RATIFICACIÓN POR ESPAÑA DE LOS PROTOCOLOS DE 1988 Y 1991}

Tras la ratificación de la CSE originaria, España en el año 1991 procede a denunciar, al amparo del art. 37 del Tratado, el art. 8.4 b) de la CSE ${ }^{45}$. El referido precepto obligaba a las Partes contratantes a prohibir el empleo femenino en trabajos subterráneos de minería $y$, en su caso, en cualesquiera otros trabajos que no sean adecuados para la mujer por su carácter peligroso, penoso e insalubre. La denuncia del reseñado art. 8.4 b) se formulaba con el fin de hacer compatible la interpretación que de la regulación del trabajo de la mujer se había impuesto en España, con el compromiso asumido internacionalmente a través de la CSE. En este sentido, tras la entrada en vigor de la CE, surgieron dudas sobre la constitucionalidad de la prohibición de determinados trabajos a las mujeres contenidos en distintas normas jurídicas. Se plateaba si dichas prohibiciones, de carácter genérico e indiscriminado y aplicables a las mujeres por su propia condición de mujer, resultaban conformes al principio de igualdad y no discriminación recogido en el art. 14 de nuestro

\footnotetext{
${ }^{41}$ En palabras del presidente del Consejo de Europa, Karl Czernetz. El País, 13 de octubre de 1977.

${ }^{42}$ Instrumento de Ratificación de 29 de abril de 1980, de la Carta Social Europea, hecha en Turín de 18 de octubre de 1961, BOE, 26 de junio de 1980, y Corrección de errores del Instrumento de Ratificación, de 29 de abril de 1980, de la Carta Social Europea, hecha en Turín el 18 de octubre de 1961, BOE, 11 de agosto de 1980.

${ }^{43}$ RODRÍGUEZ PIÑERO, M., "La Carta Social Europea y su puesta en práctica", Revista de Instituciones Europeas, vol. 5, n 1 (1978), p. 82.

44 SALCEDO BELTRAN, C., Reformas legislativas, incumplimientos de la Carta Social Europea y su invocación en los órganos judiciales, op. cit., p. 10, y JIMENA QUESADA, L., "El último bastión en la defensa de los derechos sociales: la Carta Social Europea", RJUAM, nº 29 (2014), p. 174.

45 BOE, 10 de mayo de 1991.
} 
texto constitucional. Tanto la jurisprudencia como la doctrina se mostraba inicialmente discrepante sobre este asunto ${ }^{46}$.

Finalmente, y como no podía ser de otro modo, se impuso la interpretación que las prohibiciones de realizar concretos trabajos peligrosos o insalubres solo debían predicarse en relación con la maternidad, no siendo admisible la prohibición de determinadas labores por el mero hecho de ser mujer ${ }^{47}$. Ello implicaba necesariamente la denuncia del art. 8.4 b) de la CSE, que formulaba las prohibiciones del trabajo femenino con carácter general, sin ligarlo a la maternidad. La interpretación mantenida por España, y que le llevó a denunciar el referido precepto de la CSE, no solo era más acorde con el ordenamiento jurídico interno, sino que era el resultado necesario de un cambio de concepción que, superando lo jurídico, se insertaba de lleno en los nuevos paradigmas de organización social, cimentados en los principios de igualdad y no discriminación. Se incorporaba de este modo a nuestro sistema jurídico el principio de neutralidad por razón de sexo en materia de seguridad y salud laboral ${ }^{48}$.

España firmó el Protocolo adicional de 1988 el 5 de mayo de 1998 y lo ratificó el 24 de enero del año 2000, entrando en vigor el 23 de febrero de ese mismo año ${ }^{49}$. En relación con esta ratificación, el Consejo de Estado se pronuncia en su Dictamen previo el 25 de febrero de 1999 (expediente 348/1999), señalando que el Protocolo objeto de consulta "no sólo no plantea problemas de aplicación en España sino que concuerda en buena medida con las previsiones y objetivos del Derecho interno, de modo que su ratificación no implicará la necesidad de modificar la legislación vigente". Aun así, y teniendo en cuenta que el protocolo "incide sobre derechos y deberes establecidos en el Título I de la Constitución (artículos 14, 35, 37, 40 y 50) y que recae sobre materias reguladas por Ley en el ordenamiento español, ha de estimarse comprendido en los párrafos c) y e) del artículo 94.1 de la Constitución, con el consiguiente requerimiento de autorización de las Cortes Generales previa a su conclusión".

En relación con el Protocolo de enmienda, el mismo fue firmado por España el 21 de octubre de 1991, depositando nuestro país el instrumento de ratificación el 24 de enero de 2000. Previamente, el Consejo de Estado había emitido su Dictamen el 18 de marzo de 1999 (expediente 346/1999), indicando que el reseñado Protocolo "introduce ciertas

\footnotetext{
${ }^{46}$ Vid. FERNÁNDEZ MARCOS, L., "El principio de no discriminación por razón de sexo y los trabajos prohibidos a la mujer en la legislación de seguridad e higiene”, Actualidad Laboral, n 1 (1990), pp. 2 y 3. ${ }^{47}$ Cfr. STC 229/1992, de 14 diciembre (rec. amparo 2281/1989).

${ }^{48}$ LÓPEZ RUBIA, E., "De una legislación proteccionista a una normativa neutra en materia de prevención de riesgos laborales”, Lan Harremanak, no 23 (2010-2011), pp. 77 y ss. y ALEMANY ZARAGOZA, E., "Evolución histórica del trabajo de la mujer hasta nuestro días", Aranzadi Social, no 5 (2004), pp. 14931510.

${ }^{49}$ Instrumento de ratificación por parte de España del Protocolo Adicional a la Carta Social Europea, hecho en Estrasburgo el 5 de mayo de 1988, BOE, 25 de abril de 2000, y Corrección de errores del Instrumento de ratificación por parte de España del Protocolo Adicional a la Carta Social Europea, hecho en Estrasburgo el 5 de mayo de 1988, BOE, 13 de septiembre de 2000.
} 
modificaciones en relación a las funciones, órganos y funcionamiento de los mecanismos institucionales previstos originariamente, dando carta de naturaleza positiva a algunas prácticas que ya se vienen observando. Aunque ello no signifique una alteración radical de la estructura ni de las funciones actuales ejercidas, teniendo en cuenta la importancia política que tiene la Carta de Turín de 1961 en el ámbito de los derechos económicos y sociales y los esfuerzos por proveer a su mayor protección en el ámbito del Consejo de Europa, puede considerarse que el Protocolo de Enmienda de dicha Carta se sitúa en ese plano de trascendencia política, quedando así comprendido en el párrafo a) del artículo 94.1 de la Constitución". Es por ello que "la prestación del consentimiento del Estado para obligarse por medio del Protocolo de Enmienda a la Carta Social Europea, hecho en Turín el 21 de octubre de 1991, requiere la previa autorización de las Cortes Generales".

Como se ha apuntado anteriormente, la entrada en vigor del Protocolo de enmienda no se ha producido, al exigir para su eficacia la unanimidad de todos los Estados que eran Partes contratantes de la CSE en aquel momento (1991); consentimiento que aún no se ha producido en el caso de Dinamarca, que ni siquiera lo ha firmado, y de Reino Unido y Luxemburgo, que lo han firmado, pero no ratificado. Es esta la razón, y no otra, por la que la ratificación de este Protocolo no se ha publicado en el $B O E$, pues si así se hubiera hecho, daría la falsa apariencia de que forma parte del ordenamiento jurídico interno, ex. art. $96 \mathrm{CE}$, un tratado que aún no tiene vigencia. Solo en el momento que el Protocolo de enmienda sea ratificado por los tres países citados, procederá la publicación en el BOE de la ratificación de España, no formando parte de nuestro ordenamiento jurídico interno hasta que ese hecho se produzca.

\section{ESPAÑA Y SUS RETOS PENDIENTES: EL PROTOCOLO DE RECLAMACIONES COLECTIVAS Y LA CARTA SOCIAL EUROPEA REVISADA}

España no ha firmado ni ratificado el Protocolo adicional de 1995 regulador del sistema de reclamaciones colectivas, ni ha ratificado la CSE revisada, lo que sitúa a España en el nivel más bajo de compromiso con la CSE entre los posibles ${ }^{50}$.

La ausencia de firma y ratificación del Protocolo de 1995 impide acudir a España al procedimiento de reclamaciones colectivas, lo que limita sustancialmente la efectividad de la CSE en nuestro país. Este hecho ha generado numerosas críticas, pues evidencia la limitada implicación de España con los derechos recogidos en la $\operatorname{CSE}^{51}$, y excluye un mecanismo de control con "enorme potencial de justiciabilidad y efectividad en su funcionamiento" ${ }^{52}$. La aceptación del procedimiento de reclamaciones colectivas puede

\footnotetext{
50 JIMENA QUESADA, L. y SALCEDO BELTRÁN, C., "Desafíos para la...", op. cit., p. 277.

${ }^{51}$ BAJO GARCÍA, I., "La reforma laboral a la luz de la Carta Social Europea. Convergencias y divergencias entre el Tribunal Constitucional y el Comité Europeo de Derechos Sociales", Revista General de Derecho del Trabajo y de la Seguridad Social, no 40 (2015), p. 158.

52 JIMENA QUESADA, L. y SALCEDO BELTRÁN, C., "Desafíos para la...", op. cit., p. 279.
} 
entenderse como "una gran asignatura pendiente para España", que está sometida exclusivamente al control efectuado en el marco del sistema de informes, obligatoriamente impuesto por la CSE originaria ${ }^{53}$.

Respecto a la CSE revisada, España la firmó el 23 de octubre de 2000, sin que hasta la fecha haya sido ratificada. Con todo, la ausencia de ratificación de la CSE revisada no debe llevar a entender que la norma no resulta eficaz en nuestro ordenamiento jurídico interno, pues todos los derechos laborales reconocidos en la versión originaria siguen teniendo plena vigencia en España, pudiendo ser alegados en la jurisdicción interna.

Previamente a su firma, el 26 de noviembre de 1999, la Secretaría General Técnica del Ministerio de Trabajo y Asuntos Sociales elaboró un informe sobre la CSE revisada en el que subrayaba que, a excepción de los arts. 2.3 (derecho a conceder vacaciones anuales pagadas de cuatro semanas como mínimo) y 3.4 (promover el establecimiento progresivo de servicios de higiene en el trabajo para todos los trabajadores, con funciones esencialmente preventivas y de asesoramiento), el reconocimiento a nivel supranacional de nuevos derechos "no plantea problemas de aplicación en nuestro país, ya que concuerda con nuestro derecho interno, por lo que su ratificación no implicaría la necesidad de modificar nuestra legislación".

Recogiendo parte de los razonamientos del informe más arriba referido, el Dictamen del Consejo de Estado de 11 de mayo de 2000 (expediente $n^{0}$ 1740/2000), señala a este respecto que "la ratificación de la Carta Social Europea revisada no sólo no plantea problemas de aplicación en España sino que concuerda en buena medida con las previsiones y objetivos del Derecho interno, de modo que su ratificación no implicará la necesidad de modificar la legislación vigente. Ciertamente existen algunas previsiones (así las contenidas en los artículos 2.3 y 3.4) no asumidas por el Derecho interno aún, si bien, por otra parte, no son de necesaria aceptación a tenor de lo dispuesto en el artículo A.1 de la propia Carta Social Europea revisada". Además, y como no podía ser de otro modo, dispone que "teniendo en cuenta que se está ante un tratado internacional que incide sobre derechos y deberes fundamentales establecidos en el Título I de la Constitución (artículos 14, 35, 37, 40 y 50) y que recae sobre materias reguladas por Ley en el ordenamiento español, ha de estimarse comprendido en los párrafos c) y e) del artículo 94.1 de la Constitución, con el consiguiente requerimiento de autorización de las Cortes Generales con carácter previo a su conclusión".

53 JIMENA QUESADA, L., "El último bastión...", op. cit., p. 187. En el mismo sentido, JIMÉNEZ GARCÍA, F., "La protección internacional de los derechos sociales y económicos. Avances recientes; técnicas de aplicación y propuestas de reforma constitucional", Revista Europea de Derechos Fundamentales, $\mathrm{n}^{\circ} 25$ (2015), pp. 45-46. 
Pese a que, como se ha aludido, España firmó la CSE revisada el 23 de octubre de 2000, ésta aún no ha sido ratificada. La ausencia de ratificación de España ha generado numerosas críticas, tanto desde la doctrina como desde los agentes sociales ${ }^{54}$.

No parece que exista ningún impedimento jurídico para incorporar la CSE revisada ni el Protocolo de 1995 al ordenamiento interno, tal y como se desprende de los dictámenes del Consejo de Estado más arriba mencionados. Resulta paradójico que no se incorporen a nuestro ordenamiento textos convencionales que no hacen sino reforzar los derechos que ya están reconocidos en nuestro sistema jurídico interno, máxime cuando los referidos derechos "se encuentran prácticamente de forma idéntica recogidos en la Carta de los Derechos Fundamentales de la Unión Europea", de obligada aplicación para España desde la entrada en vigor del Tratado de Lisboa ${ }^{55}$. En refuerzo de lo anterior, carece de lógica interna la actuación de España en relación con la protección internacional de los derechos sociales, si se compara la resistencia mostrada a ratificar la CSE revisada y el Protocolo de 1995, con la rápida ratificación efectuada por nuestro país del Protocolo Facultativo al Pacto de Derechos Económicos, Sociales y Culturales de la ONU, adoptado por la Asamblea General el 10 de diciembre de 2008. España fue el primer país europeo, y el tercero a nivel mundial, en ratificar el mencionado Protocolo, el 23 de septiembre de $2010^{56}$.

La inexistencia de argumentos jurídicos que impidan la ratificación de la CSE revisada por España, debe llevar a pensar que la ausencia de ratificación solo puede imputarse a una inexistente voluntad política al respecto. Lo mismo puede predicarse respecto a la firma y ratificación del Protocolo de reclamaciones colectivas de $1995^{57}$.

Parece que criterios de oportunidad política invitan a los poderes públicos a no ratificar la CSE revisada y el Protocolo de 1995 hasta este momento; criterios de oportunidad que en otro contexto histórico aconsejaron la rápida ratificación de España de la CSE originaria, tan solo cinco meses después de su adhesión al Consejo de Europa, como muestra evidente del proceso de democratización que se estaba viviendo en España y del compromiso que se mantenía con el reconocimiento y la garantía de los derechos sociales. Cuatro décadas después, parece que la voluntad política es otra.

Los diferentes partidos políticos, actores esenciales en nuestro sistema democrático, han mantenido una postura relativamente ambigua respecto a la CSE. Desde un punto de vista

\footnotetext{
${ }^{54}$ Por todos, JIMENA QUESADA, L., "Retos pendientes del estado social español...", op. cit., pp. 41 y ss.

${ }^{55}$ Instrumento de Ratificación del Tratado por el que se modifican el Tratado de la Unión Europea y el Tratado Constitutivo de la Comunidad Europea, hecho en Lisboa el 13 de diciembre de 2007, BOE, 27 de noviembre de 2009.

${ }^{56}$ JIMENA QUESADA, L., "La protección internacional de los derechos sociales y laborales: la Carta Social Europea y el Comité Europeo de Derechos Sociales", Revista de Derecho Social, no 65 (2014), p. 14.

${ }^{57}$ Cfr. JIMENA QUESADA, L., "Retos pendientes del estado social español...", op. cit., pp. 51-59.
} 
programático y de principios, todos los partidos, sin excepción, han venido proclamando la naturaleza de la CSE como pilar fundamental de nuestro Estado democrático, social y de Derecho y el compromiso de España con el Tratado. Sin embargo, ninguno de los partidos políticos que han ejercido funciones de gobierno han materializado este compromiso con la CSE mediante la ratificación del Protocolo de 1995 y la CSE revisada.

\section{EL (PEN)ÚLTIMO INTENTO: EL TÍMIDO E INCOMPLETO COMPROMISO DEL ACUERDO DEL CONSEJO DE MINISTROS DE 1 DE FEBRERO DE 2019}

Tras varias décadas de preterición e insignificancia práctica, desde el año 2012 la CSE entra de lleno en la escena jurídica y política, y en sede parlamentaria se suceden debates en torno a su alcance, vinculación y el posicionamiento de España en relación con la misma.

Varias pueden ser las razones que justifican este repentino acercamiento de la clase política a un instrumento internacional, que, no le había suscitado hasta entonces ningún tipo de interés. La crisis económica y social por la que atraviesa España en el momento referido, con reformas laborales ausentes del consenso necesario por parte de los actores sociales y que implicaban la laminación de derechos laborales individuales, y, lo que es más trascendente, colectivos, llevaron a poner en primer plano de la agenda política a los derechos sociales ${ }^{58}$. Consecuencia más o menos directa de ello, la irrupción en la escena parlamentaria de nuevos partidos políticos con un fuerte compromiso programático, al menos teórico, con la defensa y garantía de los derechos de los trabajadores, conformaron un sustrato óptimo para que se evidenciara, por fin, la trascendencia de la CSE en el ámbito político.

La culminación del proceso de empoderamiento de la CSE se desencadenó definitivamente por la labor de jueces y tribunales. Diferentes órganos jurisdiccionales, cuestionando las reformas laborales operadas en España, y especialmente la Ley 3/2012, de 6 de julio, de medidas urgentes para la reforma del mercado laboral, proceden a aplicar la CSE como estándar de protección más favorable, declarando inaplicable la legislación nacional en algunos de los casos enjuiciados, por ser contraria al compromiso internacional asumido por España. De este modo, algunas resoluciones judiciales se alejan del uso residual de la CSE y se inicia una tímida corriente de resoluciones judiciales que optan por la aplicación directa de la misma, ya no como un tratado de referencia, consulta, o apoyo argumental, sino como una norma más integrada en el ordenamiento jurídico español, susceptible de ser aplicada directamente en la resolución de las diferentes controversias que puedan plantearse en sede jurisdiccional. La primera

58 Cfr. DELGADO DEL RINCÓN, L. E., "El Estado social y la fragilidad de los derechos sociales en tiempos de crisis económica", Estudios de Deusto, vol. 61, nº 2 (2013), pp. 43-68, y MONEREO PÉREZ, J.L., "El derecho del trabajo y el legislador de la crisis económica. Técnica legislativa y política de derecho social", Revista General de Derecho del Trabajo y de la Seguridad Social, no 38 (2014), pp. 1-77. 
resolución judicial que procede a aplicar directamente la CSE en detrimento de la legislación interna, fue la Sentencia $\mathrm{n}^{\circ} 412$ del Juzgado de lo Social, $\mathrm{n}^{\circ} 2$ de Barcelona, de 19 de noviembre de 2013, que estima la demanda de un trabajador que había suscrito un contrato indefinido de apoyo a los emprendedores al amparo del RDL 3/2012, y que fue resuelto por el empleador dentro del periodo de prueba de un año previsto en la referida norma ${ }^{59}$. Esta resolución, lejos de tratarse de un pronunciamiento judicial aislado, supone el punto de partida para distintas sentencias que se irán sucediendo en los años siguientes, y que implican la aplicación real y directa del contenido de la $\operatorname{CSE}^{60}$.

Esta nueva orientación, latente en los órganos jurisdiccionales de primera y, en menor medida, también de segunda instancia, no ha sido aún aceptada por el Tribunal Supremo, que, siguiendo una línea argumentativa más tradicional, continúa inadmitiendo los recursos de casación en unificación de doctrina que utilizan las decisiones y conclusiones del CEDS para alegar la existencia de contradicción respecto a resoluciones derivadas de los órganos jurisdiccionales nacionales ${ }^{61}$.

Alentados por las decisiones judiciales, y con cierto oportunismo político, diferentes partidos políticos han venido cuestionando la eficacia real de la CSE en España y el cumplimiento por nuestro país de los compromisos sociales internacionalmente asumidos. Fruto de estas circunstancias, en los últimos años se han ido reproduciendo actuaciones en sede parlamentaria con la finalidad esencial de exigir la ratificación por España de la CSE revisada, a la que en puntuales ocasiones se añade la firma y ratificación del Protocolo de reclamaciones colectivas de 1995.

La última de estas acciones adquiere especial relevancia por su origen, al emanar directamente del Gobierno. El 1 de febrero de 2019, el Consejo de Ministros aprobó el Acuerdo por el que se dispone la remisión a las Cortes Generales de la Carta Social Europea revisada y se autoriza la manifestación del consentimiento de España para obligarse por dicha carta. Sin desconocer la trascendencia del acuerdo adoptado, el alcance del mismo, que se centra exclusivamente en la CSE revisada dejando fuera al Protocolo de reclamaciones colectivas de 1995, evidencia que el compromiso de España con la CSE es aún parcial. Como ha sido apuntado, el Protocolo de reclamaciones

\footnotetext{
${ }^{59}$ Sobre este punto, vid. GARCÍA-PERROTE ESCARTÍN, I., "Carta de los Derechos Fundamentales de la Unión Europea, Carta Social Europea y reforma laboral española. A propósito de la duración del periodo de prueba del contrato de trabajo de apoyo a los emprendedores", Trabajo y Derecho: nueva revista de actualidad y relaciones laborales, $\mathrm{n}^{\circ} 15$ (2016), pp. 18-44.

${ }^{60}$ Entre otras, sobre el periodo de prueba del contrato indefinido de apoyo a los emprendedores, vid. SJS n ${ }^{\circ}$ 1 de Tarragona, de 2 de abril de 2014, SJS no 1 de Toledo, de 27 de noviembre de 2014, y la SJS no 9 de Las Palmas de Gran Canaria, de 31 de marzo de 2015. En relación con la consideración de las guardias localizadas como tiempo de trabajo, cfr. SJS $n^{\circ} 3$ de Barcelona, de 27 de octubre de 2015, STSJ Canarias, de 28 de enero de 2016 (rec. $n^{\circ}$ 581/2015), STSJ Castilla y León (Valladolid), de 19 de diciembre de 2016 (rec. no 2099/2016), y STSJ Canarias, de 31 de enero de 2017 (rec. no 1300/2016).

${ }^{61}$ Por todos, vid. Autos del TS, de 4 de noviembre de 2015 (rec. no 926/2015) y de 7 de noviembre de 2017 (rec. $n^{\circ}$ 2234/2017).
} 
colectivas constituye el procedimiento de control de la CSE más importante y eficaz, teniendo en cuenta la celeridad y simplicidad en su tramitación y su consecuente potencial de justiciabilidad y efectividad ${ }^{62}$. De este modo, el Acuerdo del Consejo de Ministros de 1 de febrero de 2019 no hace sino perpetuar el doble discurso político tradicional en nuestro país en relación con la CSE: se trasluce un compromiso teórico con los derechos sociales, pero se esquiva la vinculación de España con los mecanismos que facilitan su garantía real y efectiva.

\section{A MODO DE CONCLUSIÓN}

Como se ha podido constatar, la relación de España con la CSE ha venido marcada por la indiferencia y por la carencia de compromiso. Cuando en 1978 España se adhiere al Tratado, las esperanzas eran muchas. El momento histórico que se estaba viviendo en nuestro país se proyectaba en un deseo de unión con Europa, en un sentimiento de pertenencia hacia un proyecto colectivo que, rápidamente, se va a anclar en un plano más simbólico que real.

Durante estas cuatro décadas, la CSE ha ido penetrando en nuestro ordenamiento jurídico de forma fragmentada, esporádica y con escasa coherencia. Las razones que pueden explicar esta situación son muchas, pero, sobre todas ellas, la escasa relevancia que ha venido teniendo la CSE en España se anuda necesariamente al exiguo interés que desde el poder político ha despertado este Tratado. Prueba de ello es que España se haya venido negando de forma sistemática a ratificar la CSE revisada y el Protocolo de reclamaciones colectivas de 1995; y ello, con independencia de la tendencia política del partido que ocupara el Gobierno en cada momento. Las pretextos que, a modo de efugio, los diferentes Gobiernos han aducido para esta ausencia de vinculación han sido muchos, desde las dificultades que implicaba el texto en relación con nuestra pertenencia a la Unión Europea, hasta la supuesta incompatibilidad de algunos preceptos con nuestro ordenamiento interno. Sobre todas ellas, el recelo que el CEDS suscita como máximo intérprete de la CSE, y la pérdida de control político sobre los derechos sociales que ello conlleva, puede ser considerado como el auténtico móvil encubierto que ha venido cimentado esta pasividad política.

El cambio operado en los últimos años como consecuencia de la aplicación directa por los órganos jurisdiccionales españoles de la CSE, ha supuesto que la misma irrumpiera en el debate público. La trascendencia política de las referidas resoluciones judiciales, que ponían en cuestionamiento la legalidad de la reforma laboral del Gobierno, han insertado a la CSE en la agenda política. Ello ha supuesto también que buena parte de la doctrina iuslaboralista tomara conciencia de la CSE, que ha pasado de ser una materia olvidada a ser objeto de análisis recurrente.

\footnotetext{
${ }^{62}$ Cfr. JIMENA QUESADA, L., "El Comité Europeo de Derechos Sociales: sinergias...", op. cit., p. 105.
} 
El alcance de este cambio de tendencia respecto a la CSE es, como se ha señalado, aún incipiente. Será necesario esperar para ponderar adecuadamente si ello obedece, como todo apunta, a una tendencia política oportunista ligada al momento histórico que se está viviendo, o, por el contrario, encarna una carga de convicción y compromiso de los poderes públicos con la CSE y con el reconocimiento y garantía efectiva de los derechos sociales en toda su amplitud.

\section{BIBLIOGRAFÍA}

ALEMANY ZARAGOZA, E., “Evolución histórica del trabajo de la mujer hasta nuestro días”, Aranzadi Social, no 5 (2004).

BAJO GARCÍA, I., "La reforma laboral a la luz de la Carta Social Europea. Convergencias y divergencias entre el Tribunal Constitucional y el Comité Europeo de Derechos Sociales", Revista General de Derecho del Trabajo y de la Seguridad Social, $n^{\circ} 40$ (2015).

BELORGEY, J.M., "La Carta Social Europea del Consejo de Europa y su órgano de control: el Comité Europeo de Derechos Sociales", Revista de Derecho Político, $\mathrm{n}^{\circ} 70$ (2007).

CARDONA RUBERT, M. B., "La situación del Estado español en relación al cumplimiento de la Carta Social Europea", Revista de Derecho Social, no 69 (2015).

CARRILLO SALCEDO, J.A., "Protección de los derechos humanos en el Consejo de Europa: hacia la superación de la dualidad entre derechos civiles y políticos y derechos económicos y sociales", Revista de Instituciones Europeas, vol. 18, nº 2 (1991).

CASTILLO DAUDÍ, M., "La Carta Social Europea treinta años después: el Protocolo de 21 de octubre de 1991", Tribuna Social, nº 27 (1993).

DELGADO DEL RINCÓN, L. E., "El Estado social y la fragilidad de los derechos sociales en tiempos de crisis económica", Estudios de Deusto, vol. 61, nº 2 (2013).

DÍEZ DE VELASCO VALLEJO, M., Instituciones de Derecho Internacional Público, Madrid, Tecnos, 15 ${ }^{\mathrm{a}}$ ed., 2005.

FERNÁNDEZ MARCOS, L., "El principio de no discriminación por razón de sexo y los trabajos prohibidos a la mujer en la legislación de seguridad e higiene”, Actualidad Laboral, $\mathrm{n}^{\circ} 1$ (1990).

GARCÍA-PERROTE ESCARTÍN, I., "Carta de los Derechos Fundamentales de la Unión Europea, Carta Social Europea y reforma laboral española. A propósito de la duración del periodo de prueba del contrato de trabajo de apoyo a los emprendedores", Trabajo y Derecho: nueva revista de actualidad y relaciones laborales, $\mathrm{n}^{\circ} 15$ (2016). 
JIMENA QUESADA, L., "El Comité Europeo de Derechos Sociales: sinergias e impacto en el sistema internacional de Derechos Humanos y en los ordenamientos nacionales", Revista Europea de Derechos Fundamentales, nº 25 (2015).

JIMENA QUESADA, L., "El último bastión en la defensa de los derechos sociales: la Carta Social Europea", RJUAM, no 29 (2014).

JIMENA QUESADA, L., "La armonización procesal europea en materia de derechos fundamentales tras el Tratado de Lisboa: el caso de los derechos sociales", en DE LA OLIVA SANTOS, A. y CALDERÓN CUADRADO, M.P., La Armonización del Derecho Procesal tras el Tratado de Lisboa, Cizur Menor, Aranzadi, 2012.

JIMENA QUESADA, L., "La Carta Social Europea como instrumento de democracia social en Europa y en España", en JIMENA QUESADA, L. (coord.), Escritos sobre derecho europeo de los derechos sociales, Valencia, Tirant lo Blanch, 2004.

JIMENA QUESADA, L., "La Carta Social Europea y la Unión Europea", Revista Europea de Derechos Fundamentales, $\mathrm{n}^{\circ} 13$ (2009).

JIMENA QUESADA, L., "La protección internacional de los derechos sociales y laborales: la Carta Social Europea y el Comité Europeo de Derechos Sociales", Revista de Derecho Social, $\mathrm{n}^{\circ} 65$ (2014).

JIMENA QUESADA, L., "Retos pendientes del estado social español: en especial, la ratificación de la Carta Social Europea revisada de 1996", Nuevas Políticas Públicas: Anuario multidisciplinar para la modernización de las Administraciones Públicas, $\mathrm{n}^{\circ} 2$ (2006).

JIMENA QUESADA, L. y SALCEDO BELTRÁN, C., "Desafíos para la protección de los derechos sociales en Europa: la Carta Social Europea", Revista de Administración Pública, vol. 47 (2016).

JIMÉNEZ GARCÍA, F., "La protección internacional de los derechos sociales y económicos. Avances recientes; técnicas de aplicación y propuestas de reforma constitucional", Revista Europea de Derechos Fundamentales, nº 25 (2015).

LÓPEZ RUBIA, E., “De una legislación proteccionista a una normativa neutra en materia de prevención de riesgos laborales”, Lan Harremanak, nº 23 (2010-2011).

MONEREO PÉREZ, J.L., "El derecho del trabajo y el legislador de la crisis económica. Técnica legislativa y política de derecho social", Revista General de Derecho del Trabajo y de la Seguridad Social, $\mathrm{n}^{\circ} 38$ (2014).

MONEREO PÉREZ, J.L., "El principio de indivisibilidad e interdependencia en el sistema jurídico internacional multinivel de garantía de los derechos fundamentales", Revista Derecho del Trabajo, n ${ }^{\circ} 15$ (2017).

MORÁN, Ma L. "La cultura política y la interpretación de las transiciones a la democracia. Notas sobre el caso español”, Política y Sociedad, nº 20 (1995). 
PASTOR ARACIL, M., "Reflexiones sobre la transición política y la consolidación democrática en España", Anuario de la Facultad de Derecho, no 2 (1992-1993).

PRIETO SUÁREZ, R., "La Carta Social Europea y el Comité Europeo de Derechos Sociales (el sistema de informes y las reclamaciones colectivas)", Revista Europea de Derechos Fundamentales, $\mathrm{n}^{\mathrm{o}} 11$ (2008).

RAMÍREZ JIMÉNEZ, M. "Reflexiones sobre la transición española a la democracia", Revista de Derecho Político, n 31 (1990).

RODRÍGUEZ PIÑERO, M., "Antecedentes, génesis y significado de la Carta Social Europea", Revista de Política Social, nº 53 (1962).

RODRÍGUEZ PIÑERO, M., "La Carta Social Europea y la problemática de su aplicación", Revista de Política Social, no 118 (1978).

RODRÍGUEZ PIÑERO, M., "La Carta Social Europea y su puesta en práctica", Revista de Instituciones Europeas, vol. 5, $\mathrm{n}^{\circ} 1$ (1978).

SALCEDO BELTRAN, C., Reformas legislativas, incumplimientos de la Carta Social Europea y su invocación en los órganos judiciales, Sevilla, Centro de Estudios Andaluces, 2015.

SANZ CABALLERO, S., "Sobre las prolongaciones sociales del Convenio Europeo de Derechos humanos: la invocación del acervo de la Organización Internacional del Trabajo en la jurisprudencia del Tribunal Europeo de Derechos Humanos", Revista General de Derecho Europeo, n ${ }^{\circ} 32$ (2014).

SEBASTÍAN LORENTE, J.J., "La idea de Europa en el pensamiento político de Ortega y Gasset", Revista de Estudios Políticos, nº 83 (1994).

SESMA LANDRIN, N. y DE HOYOS PUENTE, J., "Los procesos de transición democrática a debate", en AA.VV., Ayer y hoy. Debates, historiografía y didáctica de la historia, Valencia, Universidad de Valencia y Asociación de Historia Contemporánea, 2015.

TEIXEIRA ALVES, L., El cumplimiento de la Carta Social Europea en materia de salarios: un estudio comparado de los ordenamientos laborales portugués, español e italiano, Barcelona, Atelier, 2014.

TEROL BERCERRA, M. J., "Sobre la reforma de la Constitución Española de 1978", Lex Social, $\mathrm{n}^{\circ} 1$ (2015).

VALDÉS DAL-RÉ, F., El constitucionalismo laboral europeo y la protección multinivuel de los derechos laborales fundamentales: luces y sombras, Albacete, Bomarzo, 2016.

VIÑAL CASAS, A., "Historia de las negociaciones para el ingreso de España en el Consejo de Europa", Revista de Instituciones Europeas, v. 5, $\mathrm{n}^{\circ} 1$ (1978). 


\section{(c)) EY-NC-SA}

